
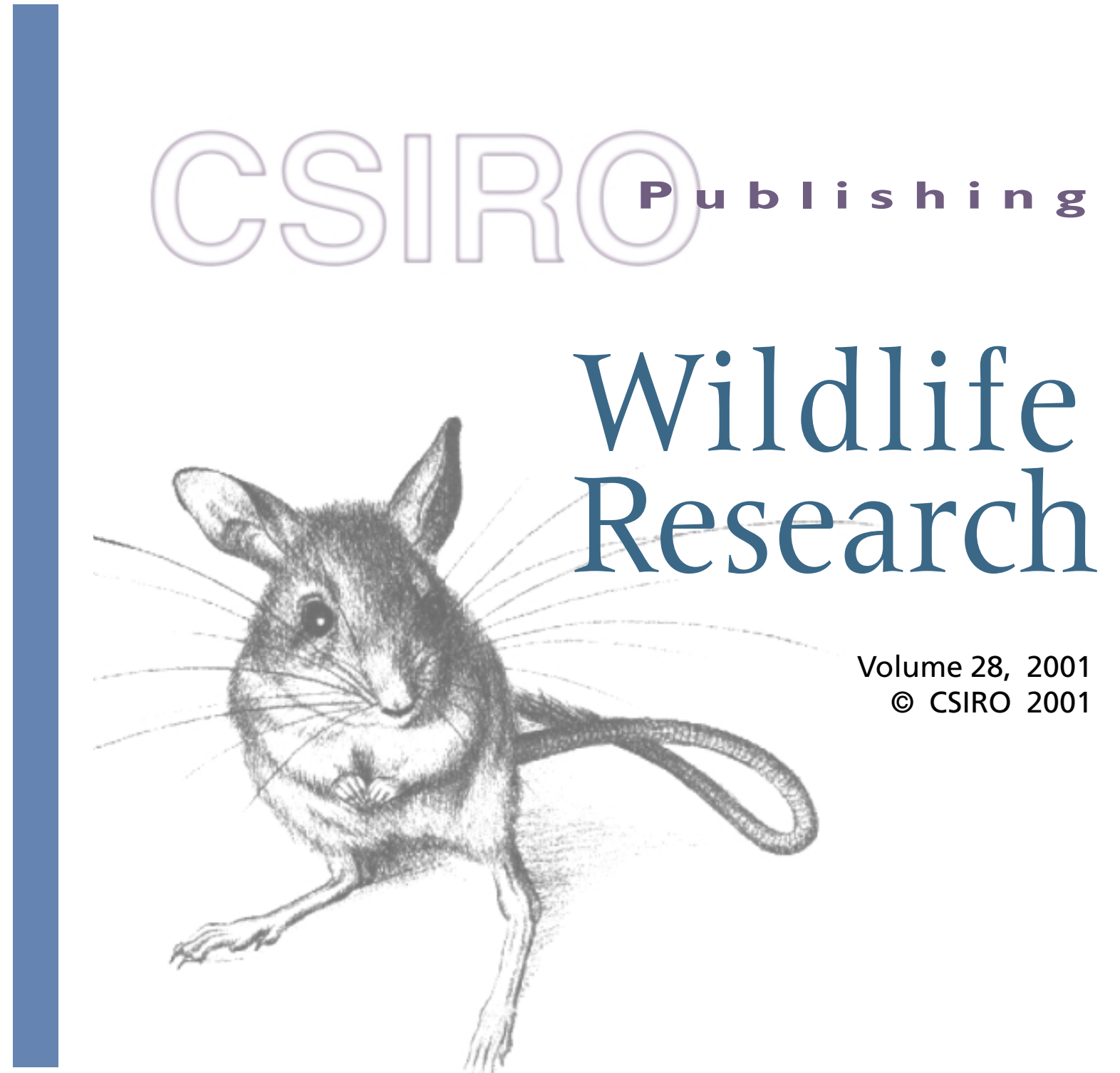

Volume 28, 2001

(C) CSIRO 2001

All enquiries and manuscripts should be directed to:

Wildlife Research

CSIRO Publishing

PO Box 1139 (150 Oxford St)

Collingwood, Vic. 3066, Australia

Telephone: +61 396627622

Fax: +6139662 7611

$\begin{array}{ll}\text { C S I RO } & \text { Email: publishing.wr@csiro.au } \\ \text { PUBLISHING } & \end{array}$

Published by CSIRO Publishing

for CSIRO and the Australian Academy of Science

www.publish.csiro.au/journals/wr 


\title{
Diet of a large carnivorous lizard, Varanus varius
}

\author{
Fiorenzo Guarino \\ Applied Ecology Research Group, University of Canberra, Canberra, ACT 2601, Australia
}

\begin{abstract}
The diet of a population of lace monitors, Varanus varius, at Lake Burrendong was examined over the spring, summer and autumn seasons. Carrion dominated the diet; it was eaten consistently in all seasons by all the monitors and was generally supplemented by live mammalian kills and invertebrates. Nestling birds and rabbits as well as bird and reptile eggs were eaten mainly during the flush periods of the spring and early summer. The data reported here agree with other reports for the genus Varanus: that they are generalist carnivorous predators and scavengers.
\end{abstract}

\section{Introduction}

Varanids are carnivorous reptiles that are distributed throughout Australia, southern Asia and Africa. The family has a wide Australian distribution, in which 30 of about 50 species are known to occur (Pianka 1995). Varanids, or monitors as they are commonly known, are powerful diurnal raptorial lizards that are characterised by an elongated muscular body, a long deeply forked tongue and a long slender snout (Auffenberg 1981; Pianka 1995; King and Green 1999). In Australia, monitors live in virtually every habitat and climatic zone (Greer 1989; Pianka 1995; King and Green 1999): some species are semi-aquatic, others terrestrial, while still others are saxicolous and/or semiarboreal or truly arboreal. Most species are wide-ranging generalist foragers and the family lacks the variety of body forms found in most other lizard families (Shine 1986).

Second to the dingo, the lace monitor, Varanus varius, is the largest carnivore in eastern Australia and is probably the largest endemic to the eastern Australian region, with body mass up to $14 \mathrm{~kg}$ (Weavers 1988). It is among the most conspicuous of reptiles in eastern Australia and an active arboreal or terrestrial forager, with a capacity for abundant aerobic activity (Bartholomew and Tucker 1964). Studies in south-eastern Australia have shown that lace monitors are generalist predators and scavengers that feed on a range of prey, including mammals, birds, fish, amphibians, eggs and insects (King and Green 1979; Losos and Greene 1988; Weavers 1989). These monitors are well known for taking advantage of situations where prey is abundant. For example, Fleay (1950) reported that a lace monitor regurgitated four fox cubs, three nestling rabbits and three large blue-tongued skinks. In another study (Weavers 1989), a 1.2-kg V. varius regurgitated a $500-\mathrm{g}$ rabbit (equating to $42 \%$ of the lizard's body mass). These reports of excessive feeding suggest that V. varius has a prodigious stomach and a big appetite (Fleay 1950; Greer 1989; Weavers 1989), presenting interesting ecological questions about prey-consumption rates in this species.

Knowledge of an organism's diet yields important information about it, and helps in assessment of the influence of season on its well being. Similarly, if the steady-state intake the organism requires, and the conditions that affect it are known, then its life-history strategies can be understood and its detailed requirements can be predicted. The objectives of this study were to determine the prey eaten by $V$. varius, their relative contributions to the diet, and how these contributions changed seasonally.

\section{Methods}

Study area

All fieldwork was conducted within the terrestrial habitats on the Mudgee side of Lake Burrendong, in central-western New South Wales, Australia $\left(32^{\circ} 40^{\prime} \mathrm{S}, 149^{\circ} 10^{\prime} \mathrm{E}\right)$. The study area comprises approximately $100 \mathrm{~km}^{2}$. The topography ranges from grassland plains to steep rugged hills.

\section{Study species}

Lace monitors are active between September and May (spring, summer and autumn) and generally inactive between June and August (winter) (Guarino, unpublished). The species is geographically distributed along the east coast of Australia, from Cape York Peninsula in Queensland to southern Victoria, and west to about the border between New South Wales and South Australia (Cogger 1993). The body size of lace monitors ranges from $0.2 \mathrm{~m}$ to over $2 \mathrm{~m}$ in length, and from $200 \mathrm{~g}$ to 
over $14 \mathrm{~kg}$ in mass (Weavers 1988). Mating occurs during the late spring, and then 6-12 eggs are laid in termitaria (Carter 1991). Hatchlings emerge the following spring.

\section{Capture}

Monitors were caught with the aid of a noose and pole apparatus. Monitors were 'noosed' up to $10 \mathrm{~m}$ from the ground using this technique. Some monitors were caught by hand, usually when observed basking or slowly climbing a tree. Large cage traps $(1.5 \times 0.4 \times 0.3 \mathrm{~m})$ baited with meat were also employed when particular individuals were required. Meat bait found in stomach samples was discarded from the dietary analysis

Upon capture, animals were marked, sexed and measured. Animals were measured by painting letter and number combinations on their dorsum using Liquid Paper ${ }^{\circledR}$. Snout-vent length (SVL) and tail length were measured to the nearest $5 \mathrm{~mm}$. Body mass was measured to an accuracy of $\pm 50 \mathrm{~g}$ at a precision of $4.2 \%$ or better using a Salter ${ }^{\circledR}$ spring balance.

\section{Diet}

Between November 1997 and September 1998, regurgitated stomach contents and faeces were collected from lace monitors. Production of these items was easily induced by normal handling of $V$. varius, so stomach flushing was not needed. All samples collected were either preserved in $95 \%$ alcohol or stored frozen. Monitors sometimes provided both a scat and a stomach sample and in such instances all the material was pooled as one sample.

In the laboratory, the contents of samples were washed in a fine sieve and constituents were sorted macroscopically into species or units of similarity where they were weighed as a proportion of total volume and their frequency of occurrence noted. The invertebrates were identified, where possible, to Order. Mammalian hair was identified to species (Brunner and Coman 1974). Reptiles and birds were usually identified to species but sometimes only to Class. Vertebrate samples that contained larvae of blowflies (Calliphoridae) were classed as carrion.

\section{Results}

In total, $33 \mathrm{~V}$. varius were captured at Lake Burrendong; of these, 21 provided a single stomach sample and another 7 provided two samples. All monitors sampled were adult males (SVL: mean $61.4 \mathrm{~cm}$, s.d. $3.7 \mathrm{~cm}$, range $57-72 \mathrm{~cm}$; Mass: mean 5164 g, s.d. 739 g, range 4100-6450 g). No ontogenetic shifts in diet were apparent.

Results from the analysis of 28 stomach and 45 faecal samples are presented in Tables 1 and 2 . The percentage volume of samples for the year were $6 \%$ invertebrate, $78 \%$ mammal (of which 51\% represented carrion), $3 \%$ reptile and
Table 1. Frequency of occurrence of taxonomic groups in samples of the stomach contents and faeces of monitors Number of samples $=73$

\begin{tabular}{|c|c|}
\hline Prey taxon & Frequency of occurrence \\
\hline \multicolumn{2}{|l|}{ Mammalia } \\
\hline \multicolumn{2}{|l|}{ Marsupialia } \\
\hline Unidentified macropod & 1 \\
\hline Macropus giganteus $^{\mathrm{A}}$ & 19 \\
\hline Sminthopsis murina & 1 \\
\hline Trichosurus vulpecula & 2 \\
\hline \multicolumn{2}{|l|}{ Artiodactyla } \\
\hline Bos taurus ${ }^{\mathrm{A}}$ & 1 \\
\hline Ovis $_{\text {aries }}{ }^{\mathrm{A}}$ & 11 \\
\hline Sus scrofa ${ }^{\mathrm{A}}$ & 3 \\
\hline \multicolumn{2}{|l|}{ Lagomorpha } \\
\hline Oryctolagus cuniculus & 17 \\
\hline \multicolumn{2}{|l|}{ Rodentia } \\
\hline Mus domesticus & 2 \\
\hline Rattus rattus & 1 \\
\hline Unidentified & 2 \\
\hline \multicolumn{2}{|l|}{ Aves } \\
\hline \multicolumn{2}{|l|}{ Psittacidae } \\
\hline Cacatua roseicapilla & 4 \\
\hline Unidentified & 2 \\
\hline \multicolumn{2}{|l|}{ Anatidae } \\
\hline Chenonetta jubata & 1 \\
\hline \multicolumn{2}{|l|}{ Reptilia } \\
\hline \multicolumn{2}{|l|}{ Agamidae } \\
\hline \multicolumn{2}{|l|}{ Unidentified eggs } \\
\hline \multicolumn{2}{|l|}{ Scincidae } \\
\hline Unidentified & 2 \\
\hline \multicolumn{2}{|l|}{ Arachnida } \\
\hline Araenae & 13 \\
\hline \multicolumn{2}{|l|}{ Hexapoda } \\
\hline Blattodea & 8 \\
\hline Coleoptera & 17 \\
\hline Orthoptera & 6 \\
\hline
\end{tabular}

${ }^{\text {A}}$ Prey type eaten as carrion

$13 \%$ bird. Overall, monitors ate 18 taxa of animal, representing four groups of prey (Table 1). It was assumed that any plant material was ingested accidentally or as a constituent of the prey.

The percentage volume of the major groups of prey varied seasonally (Fig. 1). Carrion dominated the diet of lace

Table 2. Seasonal changes in the volumetric proportion of each major taxonomic group found in the stomach contents and faeces of monitors

Data are presented as means \pm s.e. Numbers of lizards captured are shown in parentheses

\begin{tabular}{llcccc}
\hline & $\begin{array}{c}\text { Spring } \\
\text { [Sep.-Nov. } \\
(11)\end{array}$ & $\begin{array}{c}\text { Early summer } \\
{[\text { Dec.] }} \\
(21)\end{array}$ & $\begin{array}{c}\text { Mid summer } \\
{[\text { Jan.] }} \\
(11)\end{array}$ & $\begin{array}{c}\text { Late summer } \\
{[\text { Feb.] }} \\
(8)\end{array}$ & $\begin{array}{c}\text { Autumn } \\
\text { [Mar.-May] } \\
(12)\end{array}$ \\
\hline Mammal & $0.35 \pm 0.03$ & $0.58 \pm 0.09$ & $0.79 \pm 0.09$ & $0.67 \pm 0.09$ & $0.91 \pm 0.04$ \\
Bird & $0.59 \pm 0.03$ & $0.27 \pm 0.08$ & 0 & 0 & 0 \\
Reptile & 0 & $0.06 \pm 0.04$ & 0 & 0 & 0 \\
Invertebrate & 0 & $0.04 \pm 0.01$ & $0.04 \pm 0.02$ & $0.11 \pm 0.05$ & $0.02 \pm 0.01$ \\
Non-animal & $0.06 \pm 0.02$ & $0.05 \pm 0.03$ & $0.17 \pm 0.08$ & $0.22 \pm 0.09$ & $0.07 \pm 0.03$ \\
\hline
\end{tabular}




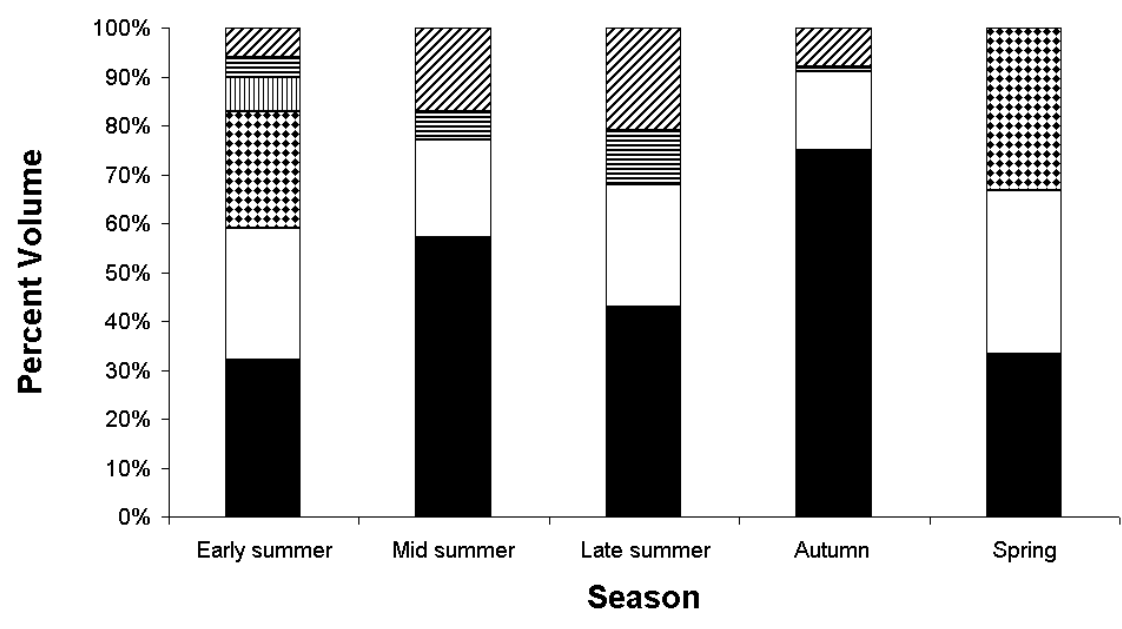

Carrion $\square$ Mammal Bird 四 Reptile 目 Invertebrate $\mathbb{Z}$ Other

Fig. 1. Seasonal changes in the mean dietary composition for $V$ varius

Table 3. Seasonal changes in the number of lace monitors that had food in the stomach at the time of capture, determined by the number of animals that regurgitated foodstuffs

\begin{tabular}{lcc}
\hline Season & $\begin{array}{c}\text { Number of } \\
\text { monitors captured }\end{array}$ & $\begin{array}{c}\text { Proportion with } \\
\text { food }\end{array}$ \\
\hline Spring & 11 & 0.27 \\
Early summer & 21 & 0.86 \\
Mid summer & 11 & 0.44 \\
Late summer & 8 & 0.14 \\
Autumn & 12 & 0.11 \\
\hline
\end{tabular}

monitors; it was eaten consistently in all seasons by all monitors and was generally supplemented by live mammalian kills and invertebrates. Nestling birds and rabbits, as well as bird and reptile eggs, were eaten mainly during the flush periods of the spring and early summer when these prey items became a conspicuous component of the environment.

The proportion of lace monitors containing prey items in their stomachs varied seasonally (Table 3 ). In general, the number of monitors containing food in their stomachs was highest in early summer, intermediate in mid-summer and spring, and lowest in late summer and autumn.

\section{Discussion}

This study confirms that lace monitors are carnivorous and opportunistic consumers of a wide range of prey, including carrion. Non-animal material (including rocks, soil, and vegetation) was likely to have been consumed as gut contents of prey or inadvertently through foraging. Newsome et al. (1983) identified three categories of prey: staples, supplementary, and opportune. These authors state that staple prey is that which predators rely on for much of the year even though this source might not always be the most abundant food type. Supplementary prey has the potential to be a major proportion of the diet at certain times of the year but generally is an ancillary component (i.e. may be infrequently available). Finally, opportune prey is those items that, although available, are not eaten regularly. Seasonal changes from staple to supplementary prey are common and have been reported particularly for mammalian predators, including dingoes (Newsome et al. 1983), cats (Molsher et al. 1999) and foxes (Catling 1988). In this study, the monitors subsisted mainly by eating carrion - their staple prey - but they took advantage of spring and early summer flushes of nestling birds, rabbits, reptiles and invertebrates as supplementary prey. Adult rabbits were opportune prey $(>1 \mathrm{~kg})$. However, carrion appears to be by far the most important food source for monitors. It is available during all periods of the year and usually becomes more common during periods of drought when herbivores generally die because of food shortages.

These dietary results for $V$. varius differ from those recorded for another population of $V$. varius. At Bendethera, in southern New South Wales, Weavers (1989) found invertebrates in $36 \%$ of stomachs of $V$. varius, reptiles in $9 \%$, mammals in $49 \%$ and birds in $6 \%$. Dietary results from another species, $V$. rosenbergi, also differed, but in that study King and Green (1979) found invertebrates in $89 \%$ of samples, reptiles in 53\%, mammals in $28 \%$ and birds in $15 \%$. The categories of food taken are similar in both populations, but they occur at different frequencies. This may be more a reflection of prey availability than of monitor preference.

At Lake Burrendong, rabbit numbers declined by $97 \%$ after the release of Rabbit Calicivirus Disease (RCD) in June 1997 and at the time of this study they remained low (7\% of pre-RCD levels) (A.E. Newsome, unpublished data). 
Because of this dramatic decline in rabbit numbers, predation on birds by monitors may be on the rise. The percentage occurrence of birds in monitor diets here was high during spring and early summer (up to $59 \%$ : Table 2). These figures are much greater than those reported by Weavers (1989) (6\% bird in samples), whose study was conducted before the release of RCD. This comparison may largely be an artefact of prey availability or of seasonality: no data were collected from which to make pre- and post-RCD comparisons. Nonetheless, this study demonstrates that predation on birds can be significant, although it is not clear whether monitors are having any noticeable negative impact on bird populations.

Overall, this work supports the hypothesis put forward by Shine (1986) and Losos and Greene (1988) that varanids opportunistically exploit the local conditions, and that different populations of the one species can show intraspecific variation in diet according to differences in the availability of prey. The data reported here agree with those reported for the genus as a whole: that they are generalist carnivorous predators (King and Green 1979; Shine 1986; Losos and Greene 1988; Weavers 1989).

\section{Acknowledgments}

I thank Adam McKeown, Steve Henry and Alex Drew for their field and technical assistance. I thank B. Green, K. Newgrain, A. Milligan and two anonymous referees for providing comments. This study was conducted under approval from the University of Canberra Animal Ethics Committee (CE8E97/18) and under permits from the NSW NPWS (B1815).

\section{References}

Auffenberg, W. (1981). 'Behavioural Ecology of the Komodo Dragon.' (University of Florida Press: Gainesville.)

Bartholomew, G. A., and Tucker, V. A. (1964). Size, body temperature, thermal conductance, oxygen consumption and heart rate in Australian varanid lizards. Physiological Zoology 37, 341-354.
Brunner, H., and Coman, B. J. (1974). 'The Identification of Mammalian Hair'. (Inkata Press: Melbourne.)

Carter, D. B. (1991). Reproductive cycle of female Varanus varius in south-eastern Australia. Mertensiella 2, 256

Catling, P. C. (1988). Similarities and contrasts in the diets of foxes, Vulpes vulpes, and cats, Felis catus, relative to fluctuating prey populations and drought. Australian Wildlife Research 15, 307-330.

Cogger, H. (1993). 'Reptiles and Amphibians of Australia.' (A. H., and A. W. Reed: Sydney.)

Fleay, D. (1950). Goannas: giant lizards of the Australian bush. Animal Kingdom 53, 92-96.

Greer, A. E. (1989). 'The Biology and Evolution of Australian Lizards.' (Surrey Beatty: Sydney.)

King, D., and Green, B. (1979). Notes on diet and reproduction of the sand goanna, Varanus gouldii rosenbergi. Copeia 1979, 64-70.

King, D., and Green, B. (1999). 'Monitors: The Biology of Varanid Lizards.' (Krieger: Malabar.)

Losos, J. B., and Greene, H. W. (1988). Ecological and evolutionary implications of diet in monitor lizards. Biological Journal of the Linnean Society 35, 379-407.

Molsher, R., Newsome, A., and Dickman, C. (1999). Feeding ecology and population dynamics of the feral cat (Felis catus) in relation to the availability of prey in central-eastern New South Wales. Wildlife Research 26, 593-607.

Newsome, A. E., Catling, P. C., and Corbett, L. K. (1983). The feeding ecology of the dingo. II Dietary and numerical relationships with fluctuating prey populations in south-eastern Australia. Australian Journal of Ecology 8, 345-366.

Pianka, E. (1995). Evolution of body size: varanid lizards as a model system. American Naturalist 146, 398-414.

Shine, R. (1986). Food habits, habitats, and reproductive biology of four sympatric species of varanid lizards in tropical Australia. Herpetologica 42, 346-360.

Ward, D. L., and Carter, D. B. (1988). Carrion feeding in Varanus varius - notes from a field study. Herpetofauna 18, 22.

Weavers, B. W. (1988). Vital statistics of the lace monitor lizard (Varanus varius) in south-eastern Australia. Victorian Naturalist 105, 142-145.

Weavers, B. W. (1989). Diet of the lace monitor Varanus varius in southeastern Australia. Australian Zoologist 25, 83-85.

Manuscript received 2 January 2001; accepted 29 March 2001 